\title{
Maintaining reliability of business processes using active monitoring techniques
}

\author{
T.J. Turner and U.S. Bititci.
}

Centre for Strategic Manufacturing

DMEM, University of Strathclyde, Glasgow, UK

Tel: +44141548 2692, Fax: +441415520557

e-mail:t.turner@dmem.strath.ac.uku.s.bititci@strath.ac.uk

\begin{abstract}
This paper introduces the concept of active monitoring of business processes to enable a business to continually satisfy key stakeholder requirements with fewer people. A case study is used to illustrate how a chemical company improved and maintained the reliability of key business processes by using active monitoring techniques.
\end{abstract}

\section{Keywords \\ Active monitoring, business process management}

\section{INTRODUCTION}

Business processes need to be maintained and improved over time because the internal and external environments that an organisation operates within continually change. Organisations need to respond quickly to these changes to ensure they continue to satisfy the expectations of their stakeholders. This paper describes how active monitoring of business processes can be used in business process management to support "lean" and "agile" organisations in their quest to survive with fewer middle managers. 


\section{WHAT IS ACTIVE MONITORING?}

Active monitoring can be defined as the process of continually interrogating selective and relevant sources of information to detect and identify early indications of potential problems (Freeman 1997). Statistical Process Control (SPC) using control charts is a well known form of active monitoring (Wheeler 1993). SPC is used extensively in manufacturing processes for measured variables of a component in order to identify trends that indicate that the process is moving towards an "out of control" condition. If the data on control charts are interpreted correctly, and the problem addressed then resolved by preventive action, the process continues to produce the desired output. In other words, action is taken on the process before an undesirable output is obtained.

Business processes consist of a series of interrelated activities, often crossing functional boundaries, with inputs and outputs. The cross functional nature of business processes makes monitoring for incipient instability of the process a complex task. In many organisations the first sign that a business process has failed to function correctly is the dissatisfaction expressed by a stakeholder of the process. Identifying which part of the process led to the failure can be a time consuming and difficult task. Traditionally this task is given to middle managers to carry out. From extensive experience accumulated over time, middle managers are able to investigate causes of failure and put things right. Often a large part of a middle manager's job involves investigation and problem solving.

In today's quest for the "lean" organisation the "buffer stock" of middle managers is being taken out to reduce cost, improve speed of communication, and increase responsiveness to customers needs. In some organisations this has led to the introduction of active monitoring systems to monitor the performance of key business processes to identify incipient instability so that preventive action, without lengthy investigation, can be taken before stakeholder dissatisfaction occurs. An example of how part of a major chemical company has gone about this is presented later.

\section{WHAT IS RELIABILITY OF A BUSINESS PROCESS ?}

Reliability engineering is extensively used in manufacturing process and product design. The same concepts can be used to explore the reliability of a business process. Reliability of a product is expressed as the probability that the product continues to meet the specification over a given time period subject to given environmental conditions (Bentley 1993). The prime function of business processes is to satisfy stakeholder requirements. It follows therefore that a reliable business process can be considered to be one that will continue to provide a high level of stakeholder satisfaction over time. Products are designed for operation in a specified operating environment and if they are not used under these conditions the warrantee becomes invalid. However business processes must 
change as the business climate changes if stakeholder satisfaction is going to be maintained. This means that the active monitoring system for a business process must identify potential problems which may lead to stakeholder dissatisfaction early enough for preventive action to be taken in order to maintain stakeholder satisfaction at a high level.

The Business Excellence Model (EFQM 1992) used for the European Quality Award contains within it the requirement that a business should identify, define, and design business processes critical for the success of the business and then manage them to provide customer satisfaction, people satisfaction, make a positive impact on society and produce good business results for the shareholders. In other words to manage critical business processes to provide stakeholder satisfaction for the major stakeholders of the business. For a business to win the award it must demonstrate trends showing high and sustained levels of stakeholder satisfaction over a five year period. It follows therefore that the reliability of critical business processes needs to be maintained and improved over this time scale for a business to be successful.

\section{MAINTENANCE OF BUSINESS PROCESSES}

Preventive maintenance is used in reliability engineering to ensure that machinery continues to function reliably. Various maintenance strategies are used depending on the criticality of the piece of equipment in the manufacturing process and the risks to the business if the manufacturing process breaks down or becomes unstable. On-condition maintenance (Bentley 1993) is used to monitor the condition of key pieces of equipment either continuously or at predetermined intervals to detect deterioration in performance. If incipient instability is detected the equipment is repaired or replaced before the reliability of the process is affected. A similar approach can be used to monitor and take preventive action on a business process before stakeholder satisfaction is threatened. To understand how to go about monitoring the condition of a business process requires an understanding of the key components of a business process.

A diagram used to describe the key components of a process (Crosby 1979) is displayed in Figure 1. The inputs to a process are of two kinds, consumable and non-consumable. For example, in a manufacturing process raw materials and energy are consumed by the process whilst equipment, procedures, skills and knowledge remain after the process has ended. The inputs are designed to produce an output that meets the requirements of the "customer" of the process. To ensure that the output from the process is reliable then the inputs to the process have to be well defined and delivered to a consistent performance standard commensurate with this aim. 


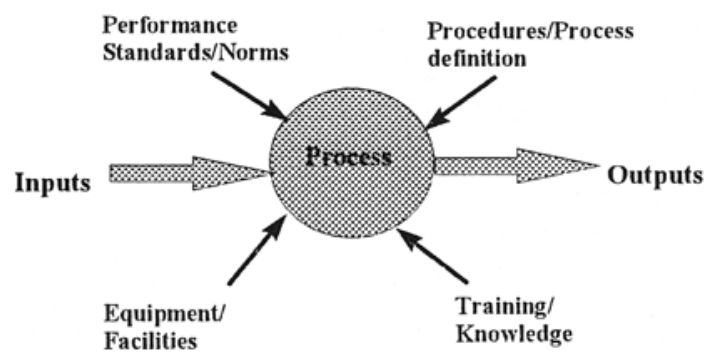

Figure 1 The Crosby process model.

For an organisation to have the confidence that the inputs to the process, both consumable and non-consumable, are not deteriorating with time, the inputs need to be actively monitored and preventive action taken when deterioration from performance standards threatens the reliability of the output. As previously mentioned SPC control charts are often used to do this. This form of active monitoring is usually associated with consumable inputs. Not all non-consumable inputs can be monitored by SPC control charting because they do not lend themselves to absolute measurement but require judgement. They can be monitored by audits against a standard, such as a written procedure, by a trained auditor. Some of these audits need to be in real-time whilst the process is in operation and other audits need to examine the objective evidence to support the validity of achievement of some performance standards after the event. For example, a critical task before an aircraft takes off is the activity in which the pilot and first officer go through a checklist together to check correct functioning of the instruments. The prime requirement of this task is that both people are present and able to confirm that they are interpreting information correctly then agreeing the outcome. This can only be audited in real-time to see if it is being done effectively. However, the flying training records of the two people involved could be audited against a training standard at anytime after the training has taken place. That is, after the event.

\section{ACTIVE MONITORING OF BUSINESS PROCESSES}

Active monitoring of business processes poses specific problems because business processes usually cross functional boundaries. Often the reason that the process breaks down and fails to deliver consistent output for the stakeholder is the lack of attention to co-ordination between functions. The objectives of one function are often in conflict with those of another function because of measurement and reward systems. Measurement and reward systems tend to operate functionally in a vertical direction in an organisation and can be in conflict with the objectives of business processes operating across functional boundaries. Actively monitoring a business process is best done by a team comprising members from all functions associated with the business process. Only then can the issues causing problems 
across functional boundaries be brought out into the open, discussed, and resolved. In traditional, functionally organised, companies this is sometimes difficult to achieve. Often the only cross-functional team meeting that occurs regularly is the monthly board meeting of directors.

An early example of the benefits of successful active monitoring of a business process is the achievement of MRPII Class " $A$ " performance to meet the requirements of the $\mathrm{ABCD}$ checklist (Oliver Wight 1986). This checklist was pioneered by the Oliver Wight organisation to encourage organisations to develop reliable order fulfilment processes. Only by anticipating problems and resolving them before they have an impact on the customer can the desired high levels of customer service be achieved to allow Class " $A$ " recognition. Using the ABCD checklist encourages organisations to re-evaluate their performance measurement systems and to remove some of the functional performance measures and replace them with process related measures. They also find that the traditional functional reporting arrangements are inadequate for speedy resolution of functional interface problems which are preventing achievement of process related performance targets. A cross-functional team organisational structure usually emerges to enable information to be shared across functions and to allow fast resolution of problems preventing achievement of the new performance targets.

\section{BENEFITS OF ACTIVE MONITORING}

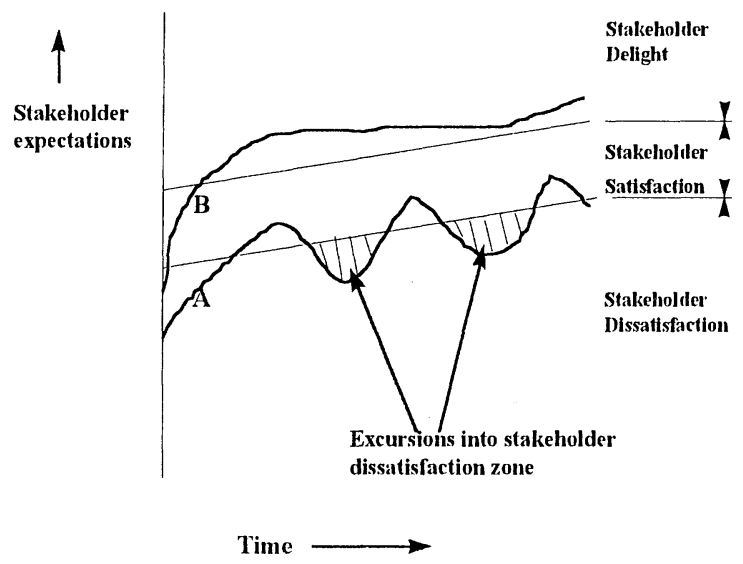

Figure 2. Effect of active monitoring on stakeholder satisfaction.

In Figure 2 the ability of two companies to satisfy stakeholder expectations is compared. Company A, without active monitoring of business processes, manages to get into the stakeholder satisfaction zone but has regular excursions into the stakeholder dissatisfaction zone over time. There is usually a lag time before the company knows it is in the stakeholder dissatisfaction zone (maybe as a result of a customer complaint for example) and then it allocates resources to recover the 
situation. Traditionally the resource allocated is from middle management but it can be from senior management if the excursion concerns a serious accident or shareholder dissatisfaction. Without active monitoring there is no way of knowing when another excursion is going to occur and so the company keeps excess middle management capacity to deal with the next excursion.

Company B, with active monitoring, manages to get into the stakeholder delight zone and stay there because as stakeholder expectations begin to change the information from active monitoring systems suggesting potential future problems is acted on and preventive action taken. Because the excursions into the stakeholder dissatisfaction zone do not occur they can operate with a smaller middle management (and often smaller senior management) team. As a consequence the organisation can function as a "lean" and "agile" organisation without the "buffer stock" of middle managers.

The benefits of an organisation similar to company B are reduced costs, increased responsiveness to stakeholders needs, improved communication between levels in the organisation and reduced risk of business failure. A company without effective active monitoring systems runs the risk of having several excursions into the stakeholder dissatisfaction zone simultaneously which stretch the middle management resources to the limit. This can result in increased risk of business failure. Apart from the extra "cost of recovery" incurred, the organisation can be diverted from pursuing the strategic objectives of the company and fall behind competitors. They can find themselves in a downward spiral because a cost cutting phase, in an attempt to catch up with competitors, often removes the "buffer stock" of middle managers because their recovery role is not understood nor recogniised.

\section{CASE STUDY}

A small business unit of a major multinational chemical company on the west coast of Scotland was threatened with closure because of poor safety and business performance. In an attempt to increase the confidence of stakeholders of the business and ensure survival an improvement programme was embarked on in the late 1980's. The first stages of the programme involved implementing an integrated business control system which involved an MRP II system. a performance appraisal system, a quality system to ISO 9001 and a SHE (Safety Health and Environment) improvement process. The business was restructured into cross-functional teams and the $\mathrm{ABCD}$ checklist used to stimulate improvement in the order fulfilment business process. Class " $A$ " standard was achieved in 1991 by introducing active monitoring systems such as cycle counting, anticipated delay reporting and works order close out analysis.

SHE improvement activity became the major focus for the company in 1990 and all operating instructions were reviewed and included in the ISO 9001 system. An active monitoring system for SHE was introduced in 1992 to monitor the 
performance of SHE systems to hold, and improve on, the already substantially improved SHE performance. The active monitoring system included the following elements.

1) A procedure for active monitoring of SHE systems was included in the document control system within the ISO 9001 quality system.

2) A training programme for all managers up to Managing Director level to explain the active monitoring system and their role in it. This included training and skills practice in leading quality systems auditing.

3) An annual SHE systems active monitoring schedule for all levels of managers to participate in at a frequency of once a month for every manager.

4) A resource to collect and collate the audit output and present findings on a visual standard at quarterly review meetings attended by cross functional teams.

5) Objectives in the performance appraisal system for $100 \%$ participation of all managers in the audit schedule to the scheduled date and for completion on time of corrective actions.

6) An annual schedule review and SHE performance improvement objective setting meeting.

The active monitoring process focused on consumable and non-consumable inputs of 12 critical SHE systems each year. System defects which had potential to lead to an undesirable output were identified and corrective and preventive actions raised. The culture within the organisation changed from inspection, in which problems were found after the system had broken down, to a prevention and system improvement culture. The SHE performance of the business unit improved to "zero harm" standard within two years and remained at that standard.

The benefit of having the procedure in the scope of the ISO 9001 system is that "on-condition" monitoring of the active monitoring system is carried out at six monthly intervals by a third party to ensure that the system is maintained and improved.

The improved reliability of the business processes across the business unit reduced the recovery activity associated with failure to achieve business plans, incident investigations, customer complaints, grievance meetings and general "fire fighting" activity. The business unit began to operate with greatly reduced levels and numbers of managers. In 1997 the business unit won the Quality Scotland quality award for business excellence.

\section{DESIGNING BUSINESSWIDE ACTIVE MONITORING SYSTEMS}

If active monitoring systems can be designed for all the core and support business processes in a business then the risk of business failure can be reduced and indeed the chances of sustaining a successful business into the future can be 
increased. Research at the Centre for Strategic Manufacturing on Integrated Performance Measurement Systems (Bititci et al 1997) and Quantitative Models for Performance Measurement Systems (Suwignjo et al 1998) has focused on identifying the key performance measures for a business and the relationships between them. The next stage in this research programme involves the development of an integrated approach to active monitoring of the critical processes in a business to ensure that the performance levels of key performance indicators are maintained at those levels needed to satisfy key stakeholders of the business. Such an integrated approach would make a business more "agile" and with the capability to actively respond to the changing business environment before stakeholders become dissatisfied with business performance.

\section{ACKNOWLEDGEMENT}

The work presented in this paper is funded by the Engineering and Physical Sciences Research Council as part of a ROPA grant.

\section{REFERENCES}

Bentley, J.P. (1993) An introduction to reliability and quality engineering. Longman Scientific and Technical

Bititci, U.S. (1997) Integrated performance measurement system: A reference model, Proceedings of the IFIP WG5.7 working conference, Ascona, Switzerland

Crosby, P.B. (1979) Quality is free: the art of making quality certain. Mcgraw Hill EFQM (1992) Self assessment guidelines for companies. European Foundation for Quality Management.

Freeman, C. (1997) Active and focused monitoring: identifying a problem before it finds you. Samford University Internet communication.

Oliver Wight (1986) ABCD Checklist. The Oliver Wight Company

Suwigno, P and Bititci, U. (1998) Quantitative models for aggregating and prioritising of performance measures. $10^{\text {th }}$ International Seminar on Production Economics, Igls, Innsbruck, Austria.

Wheeler, D.J. (1993) Understanding variation. The key to managing chaos. SPC Press

\section{BIOGRAPHY}

T J Turner is a Research Fellow at the Centre for Strategic Manufacturing. Prior to that he spent 27 years in manufacturing industry in a variety of management roles. He is an experienced European Quality Award assessor.

U. Bititci is the Director of the Centre for Strategic Manufacturing with 12 years industrial, consultancy and academic experience. 